
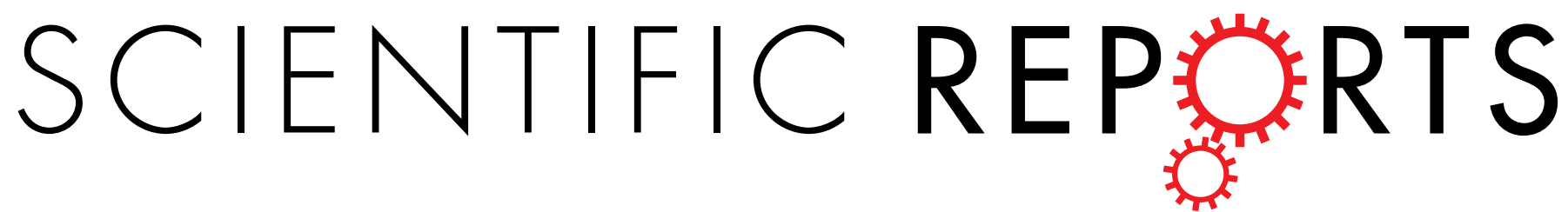

\title{
OPEN Evidence of vitamin D synthesis in insects exposed to UVb light
}

\author{
D. G. A. B. Oonincx $\mathbb{1}^{1}$, P. van Keulen ${ }^{2}$, M. D. Finke ${ }^{3}$, F. M. Baines $\mathbb{1}^{4}$, M. Vermeulen ${ }^{5,6} \&$ \\ G. Bosch ${ }^{2}$
}

Received: 18 December 2017

Accepted: 9 July 2018

Vertebrates obtain the prohormone vitamin D primarily by endogenous cutaneous synthesis under ultraviolet $b$ (UVb) exposure. To date, endogenous synthesis of vitamin D in insects has never been investigated. In an initial experiment, we exposed four insect species which differ in ecology and morphology (migratory locusts, house crickets, yellow mealworms and black soldier fly larvae (BSFL)) to a low irradiance UVb source. In a second experiment we exposed these species to a higher UV irradiance, and in a third we tested the effect of exposure duration on vitamin $D$ concentrations in yellow mealworms. Low irradiance UVb tended to increase vitamin $D_{3}$ levels in house crickets, vitamin $D_{2}$ levels in $B S F L$ and vitamin $D_{2}$ and $D_{3}$ in yellow mealworms. Higher UVb irradiance increased vitamin $D_{3}$ levels in all species but BSFL. Both BSFL and migratory locusts had increased vitamin $D_{2}$ levels. Longer UVb exposure of yellow mealworms increased vitamin $D_{2}$ and increased vitamin $D_{3}$ until a plateau was reached at $6400 \mathrm{IU} / \mathrm{kg}$. This study shows that insects can synthesize vitamin $\mathrm{D}$ de novo and that the amounts depend on UVb irradiance and exposure duration.

Vitamin D metabolites perform a hormonal function in a wide variety of animal species ${ }^{1-3}$. These animals can obtain vitamin $\mathrm{D}$ either by oral ingestion or via de novo synthesis ${ }^{4,5}$. De novo synthesis requires exposure of a vitamin D precursor to ultraviolet light with a wavelength between 280 and $320 \mathrm{~nm}(\mathrm{UVb})$, followed by a temperature dependent $\operatorname{step}^{6,7}$. Humans, birds, reptiles, amphibians and fish can use both strategies, although de novo synthesis seems the primary route to acquire a sufficient vitamin D status ${ }^{8-11}$. Ergosterol is the primary vitamin D precursor in plants, yeasts and fungi, which UVb light converts to vitamin $\mathrm{D}_{2}$, whereas 7-dehydrocholesterol (7DHC) is the precursor which forms vitamin $\mathrm{D}_{3}$ in vertebrates ${ }^{12,13}$. The vertebrate liver hydroxylates either form of vitamin $\mathrm{D}$ to 25 -hydroxycholecalciferol $(25(\mathrm{OH}) \mathrm{D})$ which is the major circulating form of vitamin $\mathrm{D}^{14}$. This can be further hydroxylated to 1,25 -dihydroxycholecalciferol $\left(1,25(\mathrm{OH})_{2} \mathrm{D}\right)$ which is the hormonally most active form of vitamin $\mathrm{D}^{14}$. This form is best known as an endocrine regulator of calcium and phosphorus metabolism in vertebrates ${ }^{15}$. However, it also serves autocrine and paracrine functions in cellular proliferation, differentiation, and apoptosis, as well as in the innate immune system ${ }^{16-21}$.

Whereas the importance of vitamin D in vertebrate physiology is well documented, little is known for invertebrates. Moreover, in the largest animal class, the insects, its metabolism has not been studied. Vitamin D has been detected in various insect species (Table 1) although its physiological role is unknown. Concentrations differ greatly between species. High concentrations of vitamin D (538 and $1444 \mathrm{IU} / \mathrm{kg}$ fresh insect) are reported for wild specimens of two species collected in the field, where they can be exposed to solar UVb radiation ${ }^{22,23}$. Most commercially produced insects have far lower vitamin D concentrations ${ }^{9,24-26}$. As these are normally not exposed to sunlight or other sources of $\mathrm{UVb}$ radiation, they likely obtain their vitamin $\mathrm{D}$ solely via the diet. Whether insects are capable of de novo synthesis is hitherto unknown. Furthermore, this animal class is highly diverse and contains species with large differences in their morphology and ecology, including their degree of exposure to solar radiation. These aspects could affect their vitamin D synthesizing capacity and hence their vitamin D content. Therefore, we conducted three experiments in which we investigated: 1) whether insect species, differing in phylogeny and ecology have the capacity to synthesize vitamin D when exposed to UVb, 2) whether exposure

${ }^{1}$ Laboratory of Entomology, Department of Plant Sciences, Wageningen University \& Research, P.O. Box 16, 6700 AA, Wageningen, The Netherlands. ${ }^{2}$ Animal Nutrition Group, Department of Animal Sciences, Wageningen University \& Research, P.O. Box 338, 6700 AH, Wageningen, The Netherlands. ${ }^{3}$ Mark Finke LLC, 17028 E Wildcat Dr, Rio Verde, AZ, 85263, USA. ${ }^{4}$ UV Guide UK, Greenfield, School Lane, Govilon, Abergavenny, NP7 9NT, Wales, UK. ${ }^{5}$ TNO Triskelion, Nutrient Analysis team, Utrechtseweg 48, Zeist, The Netherlands. ${ }^{6}$ Present address: CCIC Europe Food Test, Lelystad, The Netherlands. Correspondence and requests for materials should be addressed to D.G.A.B.O. (email: dennisoonincx@gmail.com) 


\begin{tabular}{|l|l|l|l|l|}
\hline Species & Vitamin $\mathbf{D}_{3}$ & Life stage & Origin & Reference \\
\hline Pallid-winged grasshoppers & 102 & Adults & Wild & 22 \\
\hline Rhinoceros beetles & 538 & Adults & Wild & 22 \\
\hline White lined sphinx moth & $<80$ & Adults & Wild & 22 \\
\hline Escamoles ants & 1444 & Pupae & Wild & 23 \\
\hline Superworms & $<$ LOD & Larvae & Produced & $24^{*}, 2^{* *}$ \\
\hline Giant mealworm & $<$ LOD & Larvae & Produced & $2^{*}$ \\
\hline Yellow mealworms & $<$ LOD & Larvae & Produced & $24^{*}, 25^{* *}$ \\
\hline Yellow mealworms & $<$ LOD & Adults & Produced & $24^{*}$ \\
\hline Waxworms & $<$ LOD & Larvae & Produced & $24^{*}, 25^{* *}$ \\
\hline Silkworms & $<$ LOD & Larvae & Produced & $24^{*}$ \\
\hline Cricket & $<$ LOD & Adult & Produced & $24^{*}, 25^{* *}$ \\
\hline Cricket & $<$ LOD & Nymph & Produced & $24^{*}$ \\
\hline Desert locusts & 61 & Nymphs & Produced & $9^{* * *}$ \\
\hline Desert locusts & 95 & Adults & Produced & $9^{* * *}$ \\
\hline Migratory locusts & 33 & Nymphs & Produced & $9^{* * *}$ \\
\hline Migratory locusts & 64 & Adults & Produced & $9^{* * *}$ \\
\hline House crickets & 280 & Adults & Produced & $9^{* * *}$ \\
\hline Yellow mealworms & 45 & Larvae & Produced & $9^{* * *}$ \\
\hline Black soldier fly & 100 & Larvae & Produced & 26 \\
\hline Tebo worms & $<20$ & Adults & Produced & 26 \\
\hline Turkestan cockroaches & 159 & Produced & 26 \\
\hline House flies & & Produced & 26 \\
\hline
\end{tabular}

Table 1. Literature data for vitamin $\mathrm{D}_{3}$ content (IU/kg fresh matter) of insects. *Limit of detection was $256 \mathrm{IU} / \mathrm{kg}$. **Limit of detection was $40 \mathrm{IU} / \mathrm{kg}$. ***Values recalculated assuming a dry matter content of $30 \%$.

\begin{tabular}{|l|l|l|}
\hline Diet ingredients & Vitamin $\mathbf{D}_{\mathbf{2}}$ & Vitamin $\mathbf{D}_{\mathbf{3}}$ \\
\hline Carrot (Daucus carota) & $<20$ & $<10$ \\
\hline Ryegrass (Lolium perenne) & $<20$ & $<10$ \\
\hline Wheat bran & $<20$ & $<10$ \\
\hline Mealworm feed (experiment 1) & $<20$ & 590 \\
\hline Mealworm feed (experiment 2) & $<20$ & 140 \\
\hline Chicken feed (experiment 1) & $<20$ & 12000 \\
\hline Cricket feed (experiment 2) & $<20$ & 580 \\
\hline Migratory locusts & $<20$ & $<10$ \\
\hline House crickets & $<20$ & 19 \\
\hline Yellow mealworms & $<20$ & 55 \\
\hline Black soldier fly larvae & 245 & 420 \\
\hline
\end{tabular}

Table 2. Vitamin $D_{2}$ and $D_{3}$ concentrations (IU/kg) in diets (as fed) provided to four insect species and in these species (fresh matter) at the start of experiment 1 and 2.

to a higher UVb irradiance leads to a higher vitamin D concentration, and 3) how the duration of UVb exposure affects the vitamin D concentration.

\section{Results}

None of the diet ingredients provided to the insect species contained detectable levels of vitamin $\mathrm{D}_{2}$ (Table 2). However, the complete chicken feed provided to the house crickets and BSFL in the first experiment had a high concentration of vitamin $\mathrm{D}_{3}(12,000 \mathrm{IU} / \mathrm{kg} \mathrm{DM})$. Therefore, commercial cricket feed with a lower concentration (580 IU/kg DM) was used for these species in the second experiment.

The spectral power distribution of the lamps used in the first and second experiment was similar (Fig. 1a) except in the UVa and UVb region (Fig. 1a and b). In the control treatments UVb radiation was completely blocked and UVa radiation was reduced by $44 \%$ in the first, and by $65 \%$ in the second experiment due to the glass filter. This glass filter also led to slightly lower temperatures $\left(\sim 1^{\circ} \mathrm{C}\right.$; Tables 3 and 4$)$ in the unexposed treatment.

In the first experiment $\mathrm{UVb}$ exposure greatly increased vitamin $\mathrm{D}_{3}$ concentrations (39 vs. $802 \mathrm{IU} / \mathrm{kg}$; $\mathrm{P}=0.008$ ) in the substrate-dwelling yellow mealworms (Fig. 2a). The vitamin $\mathrm{D}_{3}$ concentrations in BSFL, also a substrate dwelling species, were not affected by UVb exposure $(\mathrm{P}=0.345)$. For the above-ground living species, the $\mathrm{UVb}$ exposure had no effect on migratory locusts $(\mathrm{P}=0.310)$, whereas in house crickets vitamin $\mathrm{D}_{3}$ concentrations tended $(\mathrm{P}=0.056)$ to increase. Vitamin $\mathrm{D}_{2}$ concentrations were low or non-detectable and not affected by 

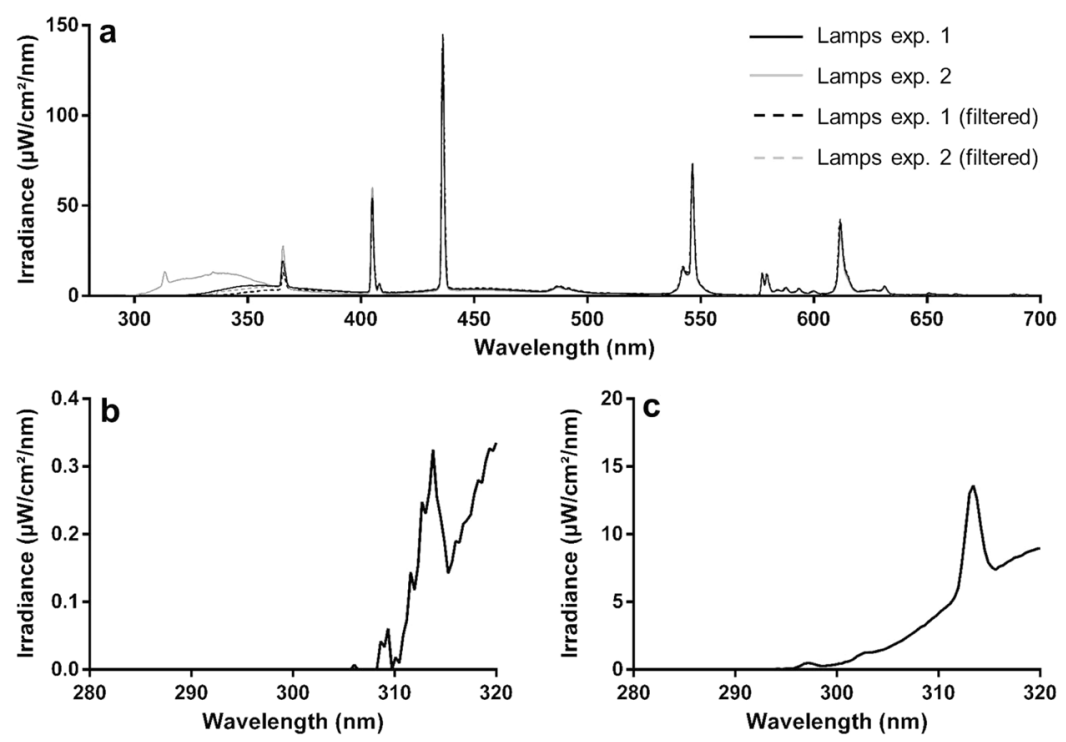

Figure 1. Spectral power distribution of the lamps used in experiment 1 and 2 , with and without a UVb filter (a) and the UVb range of lamp 1 (b) and lamp 2 (c).

\begin{tabular}{|l|l|l|l|l|l|l|l|l|}
\hline \multirow{2}{*}{ Species } & Migratory locusts & House crickets & \multicolumn{2}{l|}{ Yellow mealworms } & \multicolumn{2}{l|}{ Black soldier fly } \\
\cline { 2 - 9 } & Control & Exposed & Control & Exposed & Control & Exposed & Control & Exposed \\
\hline $\begin{array}{l}\text { UVb irradiance } \\
\left(\mu \mathrm{W} / \mathrm{cm}^{2}\right)\end{array}$ & $0.0 \pm 0.00$ & $24.2 \pm 1.56^{* *}$ & $0.0 \pm 0.00$ & $17.4 \pm 1.38^{* *}$ & $0.0 \pm 0.00$ & $14.2 \pm 1.32^{* *}$ & $0.0 \pm 0.00$ & $26.8 \pm 1.59^{* *}$ \\
\hline $\mathrm{UV}$ index & $0.0 \pm 0.00$ & $0.7 \pm 0.11^{* *}$ & $0.0 \pm 0.00$ & $0.6 \pm 0.10^{* *}$ & $0.0 \pm 0.00$ & $0.5 \pm 0.11^{* *}$ & $0.0 \pm 0.00$ & $0.8 \pm 0.12^{* *}$ \\
\hline Temperature $\left({ }^{\circ} \mathrm{C}\right)$ & $34.7 \pm 0.38$ & $35.6 \pm 0.33^{* *}$ & $27.8 \pm 0.56$ & $28.7 \pm 0.57^{* *}$ & $30.4 \pm 1.56$ & $31.3 \pm 1.49^{* *}$ & $26.3 \pm 0.65$ & $28.4 \pm 0.69^{* *}$ \\
\hline
\end{tabular}

Table 3. Environmental conditions (UVb irradiance, UV index and temperature) of four insect species exposed or not exposed (Control) to UVb radiation during the first experiment. All data are reported as mean \pm SD. $* * \mathrm{P} \leq 0.001$.

\begin{tabular}{|l|l|l|l|l|l|l|l|l|}
\hline \multirow{2}{*}{ Species } & \multicolumn{2}{|l|}{ Migratory locusts } & House crickets & \multicolumn{2}{l|}{ Yellow mealworms } & \multicolumn{2}{l|}{ Black soldier fly } \\
\cline { 2 - 9 } & Control & Exposed & Control & Exposed & Control & Exposed & Control & Exposed \\
\hline $\begin{array}{l}\text { UVb irradiance } \\
\left(\mu \mathrm{W} / \mathrm{cm}^{2}\right)\end{array}$ & $0.0 \pm 0.00$ & $90.0 \pm 5.54^{* *}$ & $0.0 \pm 0.00$ & $73.7 \pm 4.36^{* *}$ & $0.0 \pm 0.00$ & $70.1 \pm 3.10^{* *}$ & $0.0 \pm 0.00$ & $80.3 \pm 2.05^{* *}$ \\
\hline $\mathrm{UV}$ index & $0.0 \pm 0.00$ & $4.6 \pm 0.53^{* *}$ & $0.0 \pm 0.00$ & $3.5 \pm 0.28^{* *}$ & $0.0 \pm 0.00$ & $3.3 \pm 0.23^{* *}$ & $0.0 \pm 0.00$ & $3.8 \pm 0.22^{* *}$ \\
\hline Temperature $\left({ }^{\circ} \mathrm{C}\right)$ & $34.6 \pm 0.89$ & $35.5 \pm 0.63^{* *}$ & $28.1 \pm 0.50$ & $28.8 \pm 0.69^{* *}$ & $30.4 \pm 0.65$ & $31.8 \pm 0.55^{* *}$ & $30.3 \pm 0.37$ & $30.8 \pm 0.59 * *$ \\
\hline
\end{tabular}

Table 4. Environmental conditions (UVb irradiance, UV index and temperature) of four insect species exposed or not exposed (Control) to $\mathrm{UVb}$ radiation during the second experiment. All data are reported as mean $\pm \mathrm{SD}$. $* * \mathrm{P} \leq 0.001$.

exposure in the migratory locusts $(\mathrm{P}=0.151)$ and house crickets $(\mathrm{P}=1.000)$, whereas these were higher in $\mathrm{UVb}$ exposed yellow mealworms $(\mathrm{P}<0.001)$ and BSFL $(\mathrm{P}=0.008)$ (Fig. 2b).

In the second experiment, $\mathrm{UVb}$ exposure elevated vitamin $\mathrm{D}_{3}$ concentrations in migratory locusts $(0 \mathrm{vs}$. $226 \mathrm{IU} /$ $\mathrm{kg} ; \mathrm{P}=0.008$ ), house crickets (41 vs. $124 \mathrm{IU} / \mathrm{kg} ; \mathrm{P}=0.032$ ) and yellow mealworms (50 vs. $3067 \mathrm{IU} / \mathrm{kg} ; \mathrm{P}<0.001$ ) whereas those in BSFL were unaffected $(\mathrm{P}=0.548)$ (Fig. $2 \mathrm{c}$ ). Vitamin $\mathrm{D}_{2}$ concentrations increased in $\mathrm{UVb}$-exposed BSFL $(\mathrm{P}=0.008)$ and migratory locusts $(\mathrm{P}=0.008)$ and tended to be higher in UVb-exposed yellow mealworms $(\mathrm{P}=0.100)$ (Fig. $2 \mathrm{~d})$. UVb exposure did not affect vitamin $\mathrm{D}_{2}$ concentrations in house crickets $(\mathrm{P}=0.690)$.

In the third experiment a clear relationship between the duration of UVb exposure and the synthesis of vitamin $D_{3}$ and $D_{2}$ was found (Fig. 3). Vitamin $D_{2}$ concentrations increased with prolonged UVb exposure within the chosen time frame (up to 64 hours over 8 days) whereas the vitamin $\mathrm{D}_{3}$ concentration stabilised after 32 hours. Within this experiment much more vitamin $\mathrm{D}_{3}$ than $\mathrm{D}_{2}$ was produced (6400 vs. $\left.650 \mathrm{IU} / \mathrm{kg}\right)$.

\section{Discussion}

Our experiments revealed that, similar to vertebrates, some insects are capable of de novo synthesis of vitamin $\mathrm{D}_{3}$. The above-ground living migratory locusts and house crickets and the substrate dwelling yellow mealworms showed elevated vitamin $\mathrm{D}_{3}$ concentrations after exposure to UVb radiation. For the other substrate dwelling species, BSFL, UVb exposure did not elevate vitamin $\mathrm{D}_{3}$ concentrations compared to the control, although 

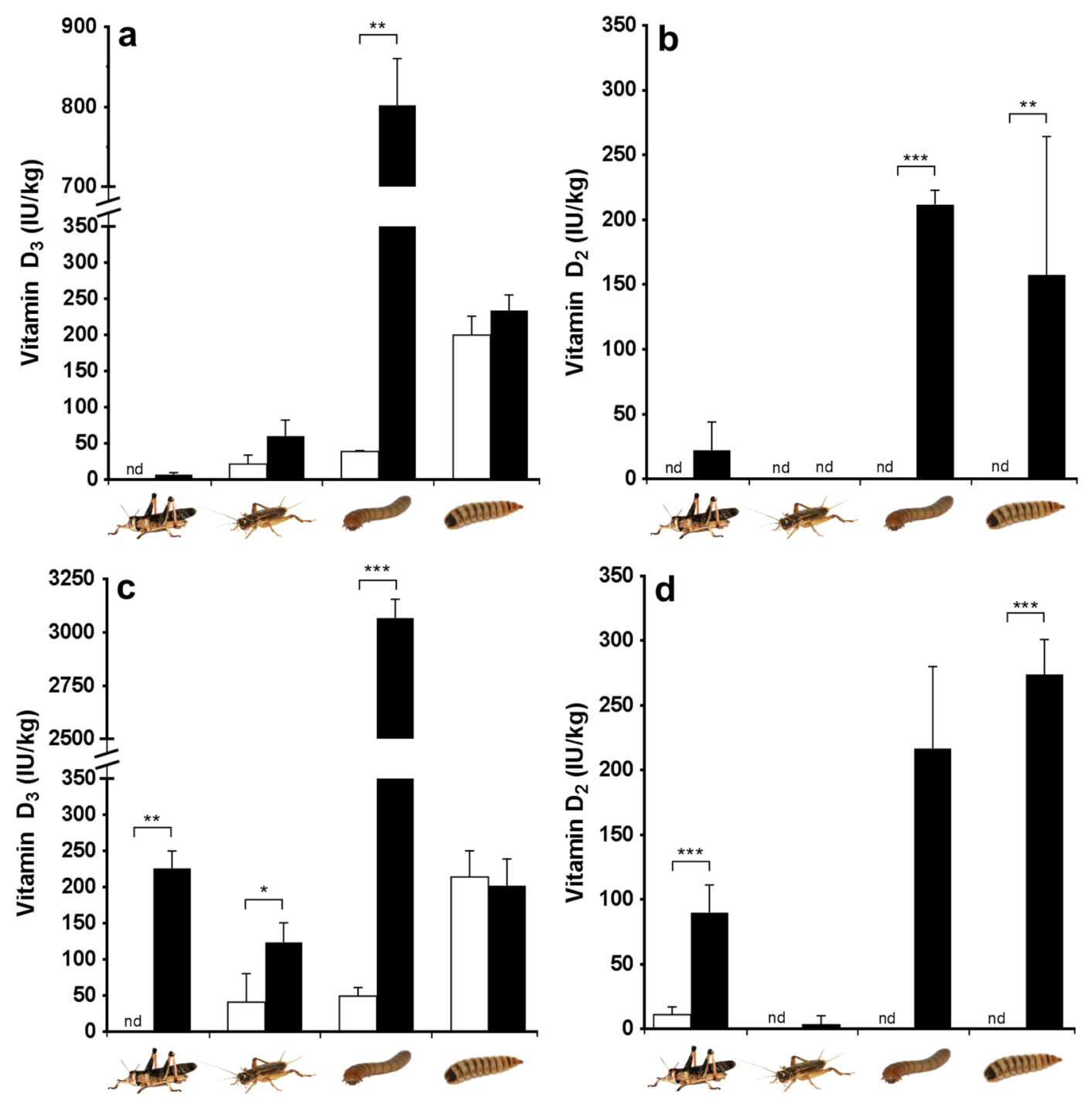

Figure 2. Vitamin $\mathrm{D}_{3}$ (a and $\mathbf{c}$ ) and vitamin $\mathrm{D}_{2}$ (panel $\mathbf{b}$ and $\mathbf{d}$ ) concentrations (IU/kg of fresh matter) of nonexposed $(\square)$ and UVb exposed ( $\square$ ) migratory locusts (Locusta migratoria), house crickets (Acheta domesticus), yellow mealworms (Tenebrio molitor) and black soldier fly larvae (Hermetia illucens) at the end of the first (a,b) and second $(\mathbf{c}, \mathbf{d})$ experiment. $\mathrm{nd}=$ not detected $(<10 \mathrm{IU} / \mathrm{kg}) ; * \mathrm{P} \leq 0.05, * * \mathrm{P} \leq 0.01, * * * \mathrm{P} \leq 0.001$; values are means $\pm \mathrm{SD}$. Photos by Mandy Decker.
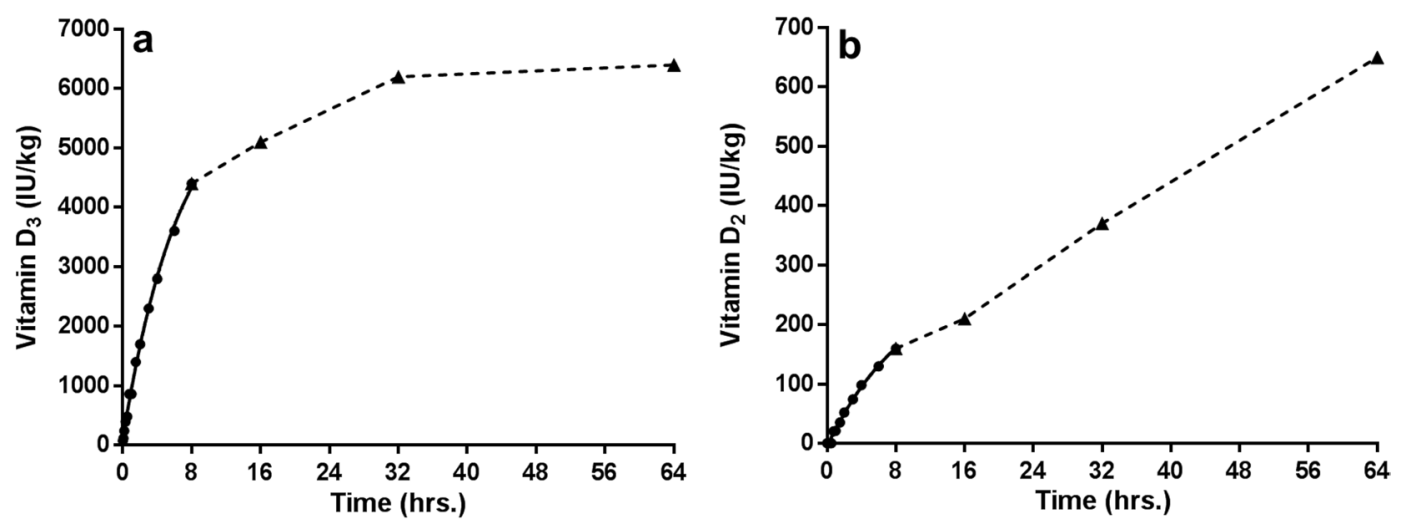

Figure 3. Vitamin $\mathrm{D}_{3}(\mathbf{a})$ and $\mathrm{D}_{2}$ (b) concentrations (IU/kg of fresh matter) in yellow mealworm larvae exposed to $\mathrm{UVb}$ radiation for varying amounts of time. Circles indicate continuous $\mathrm{UVb}$ exposure, whereas triangles indicate UVb exposure for 8 hours per day. 


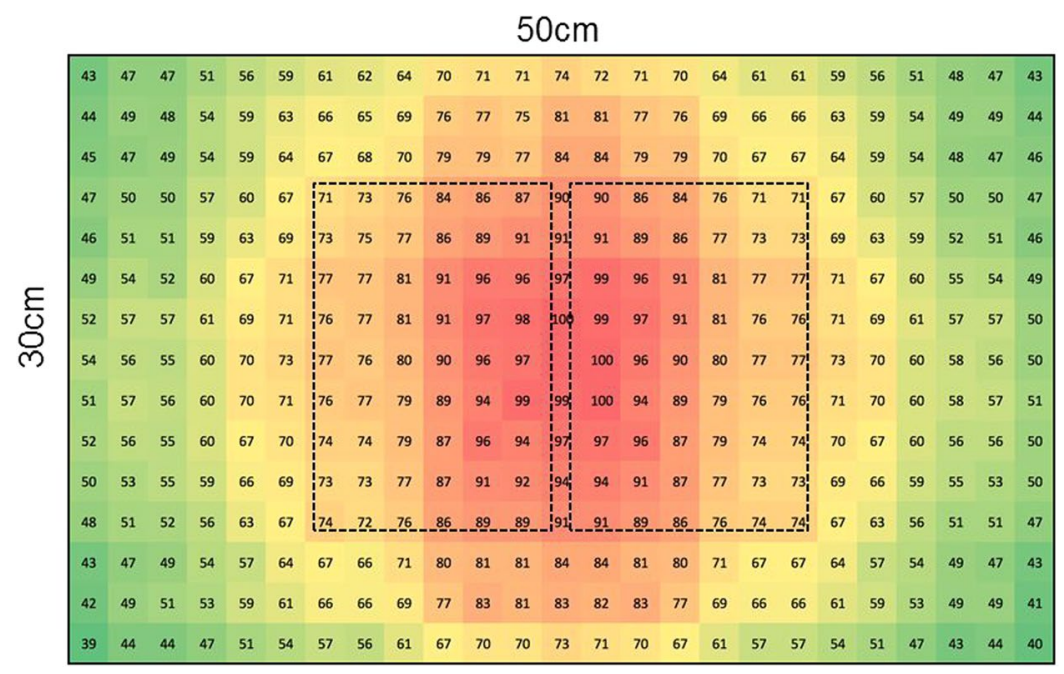

Figure 4. The spread of UVb irradiance as a percentage of the maximum measured at a distance of $11 \mathrm{~cm}$ from the light source. Dotted rectangles depict the containers used in the third experiment.

substantial concentrations were found. Furthermore, vitamin $\mathrm{D}_{2}$ concentrations were higher in UVb exposed BSFL in the first two experiments, and in migratory locusts exposed to the higher irradiance UVb (experiment 2). Yellow mealworms attained higher vitamin $D_{2}$ concentrations in both experiments, although the difference was not significant in the second experiment due to a low sample size $(n=3)$.

The vitamin $\mathrm{D}_{3}$ synthesis capacity varied between species. For instance, after the first experiment the vitamin $\mathrm{D}_{3}$ levels in house crickets were an order of magnitude greater than the levels found in migratory locusts. This is despite the fact that locusts were exposed to higher levels of UVb (Table 3) and unlike house crickets did not have access to a shelter (egg crates) from the UVb radiation. However, when locusts were exposed to the higher UVb irradiance in the second experiment their vitamin $\mathrm{D}_{3}$ levels were approximately double those found in the house crickets. The reasons for this discrepancy are unknown but there might be a species-specific UVb threshold to start vitamin D formation, which could be a function of the location of the vitamin D precursor in the insects' exoskeleton and the UVb filtering properties of their exoskeleton. Such adaptations would be functional for coping with the amount of $\mathrm{UVb}$ radiation encountered under natural circumstances; migratory locusts are a diurnal desert-dwelling species, whereas house crickets are crepuscular. Similarly, vitamin $\mathrm{D}_{3}$ synthesising capacity has been described to differ between nocturnal and diurnal gecko species ${ }^{27}$ and skin pigmentation in humans affects vitamin $\mathrm{D}_{3}$ production ${ }^{28}$. The conversion of pre-vitamin $\mathrm{D}_{3}$ to vitamin $\mathrm{D}_{3}$ depends on temperature ${ }^{6,12}$. However, the lower temperature of the unexposed insects compared to $\mathrm{UVb}$ exposed insects $\left(\sim 1^{\circ} \mathrm{C}\right)$ would only decrease the conversion rate by $\sim 2 \%{ }^{29}$.

Under our experimental conditions the UVb exposed yellow mealworms had far higher vitamin $\mathrm{D}_{3}$ concentrations than the other species tested. As there was a large difference in vitamin $\mathrm{D}_{3}$ concentrations between exposed and unexposed yellow mealworms these levels were due to UVb exposure. This species is negatively phototactic; it hides from light which would minimize UVb exposure and consequent vitamin D formation under natural conditions $^{30}$. However, in these experiments the larvae could only hide under each other and a thin layer of food and were therefore exposed to relatively high levels of UVb compared to natural circumstances. As recorded in Table 4, the maximum irradiance directly under the lamp averaged UVI 3.3. This moderate level of irradiation is within the range provided by natural sunlight and although un-natural for this species, did not have any observed negative effects upon the larvae ${ }^{31}$. Exposure to the lamp with the higher irradiance UVb lamp (experiment 2) resulted in higher vitamin $\mathrm{D}_{3}$ concentration than exposure to the lower irradiance UVb lamp (experiment 1). The yellow mealworms exposed for 8 hours or more (experiment 3 ) had a higher vitamin $\mathrm{D}_{3}$ concentration than those in the second experiment, although the latter were exposed to the same lamp for a longer period of time. This may be explained by two factors; firstly the layer of mealworms was thicker in the second $(\sim 2.0 \mathrm{~cm})$ than in the third experiment $(\sim 0.5 \mathrm{~cm})$ resulting in a larger proportion of the mealworms being continuously exposed in the latter experiment. Secondly, the UVb irradiance distribution differed between the second and third experiment due to the utilization of larger containers in the second $(50 \times 30 \mathrm{~cm}$; Fig. 4, large rectangle $)$ than in the third experiment $(11 \times 16 \mathrm{~cm}$ Fig. 4 , small rectangles). Hence, the mealworms in the third experiment were effectively exposed to a higher $\mathrm{UVb}$ irradiance than in the second experiment. If the mealworms in the third experiment were equally distributed within their container without overlapping each other, they were on average subjected to a UVb dose of $1.26 \mathrm{~J} / \mathrm{cm}^{2} /$ day. The UVb dose encountered under natural circumstance depends on many variables including location on earth, time of day, time of year, and amount of cloud cover ${ }^{32}$. The UVb dose for the US, averaged over the year, is between 1.2 and $4.1 \mathrm{~J} / \mathrm{cm}^{2} /$ day which indicates that the dosage used in this experiment are comparable to UVb dosages that can be encountered in exposed locations under natural circumstances although these dosages would be considerably higher than this negatively phototactic species would receive in its native microhabitat ${ }^{33,34}$. 
In both the second and third experiment mealworm vitamin $\mathrm{D}_{3}$ concentrations are far higher than values published for insects to date (Table 1). However, data from wild caught blister beetles (Tegrodera aloga) collected in Arizona during late spring show even higher values (8,370-11,280 IU/kg fresh insect; Mark Finke, Personal observation). These concentrations were similar to those found in tuna, salmon and mackerel, renowned for having a high vitamin $\mathrm{D}_{3}$ content ${ }^{28,35,36}$ which is believed to be acquired dietarily via several accumulation steps in the food chain ${ }^{36}$.

BSFL are known as efficient converters of organic waste, including waste colonised by fungi ${ }^{37,38}$. The moistened chicken feed provided to the BSFL prior and during the first two experiments is prone to fungal colonization at temperatures between 26 and $31^{\circ} \mathrm{C}$. The three-day old BSFL had high starting levels of vitamin $\mathrm{D}_{2}$ and $\mathrm{D}_{3}$ (Table 2). They were provided with chicken feed with a high vitamin $\mathrm{D}_{3}$ concentration (Table 2) during their first three days of life. Furthermore, they were illuminated by an array of fluorescent tubes (TLD18W840NG, Phillips, Eindhoven, the Netherlands), which emits a small fraction of UV light ${ }^{39}$. After exposure to UVb these fungi could have formed a dietary source of vitamin $\mathrm{D}_{2}$ for the BSFL. However, feed samples were not tested at the end of the experiments to ascertain fungal contamination or vitamin $\mathrm{D}_{2}$ content. At the end of the two experiments the vitamin $\mathrm{D}_{3}$ levels in both the UVb exposed and unexposed BSFL remained high. Vitamin $\mathrm{D}_{2}$ levels also remained high in exposed larvae, but were below the limit of detection in the unexposed BSFL at the end of the experiment. During larval development, BSFL grow 4000 times their starting weight ${ }^{40}$, thereby greatly diluting their initial vitamin $\mathrm{D}_{2}$ levels if deprived of UV light. Dietary vitamin $\mathrm{D}_{3}$ concentrations of the BSFL feed differed greatly $(12,000$ vs. $580 \mathrm{IU} / \mathrm{kg})$ between the first and second experiment. However, larval vitamin $\mathrm{D}_{3}$ concentrations were similar in both experiments. Why the vitamin $\mathrm{D}_{2}$ levels were higher in UVb exposed BSFL, but the vitamin $\mathrm{D}_{3}$ levels were similar in the BSFL remains to be investigated further. In vertebrates, vitamin $\mathrm{D}_{2}$ and $\mathrm{D}_{3}$ can be absorbed and metabolised differently due to differences in their binding affinity and their hydroxylation rate ${ }^{41}$. Vitamin $\mathrm{D}_{2}$ is for instance less potent than vitamin $\mathrm{D}_{3}$ in humans, monkeys and birds, whereas it is more potent in rats ${ }^{41}$. An alternative explanation for the difference in vitamin $\mathrm{D}_{2}$ concentrations in the BSFL is that this species synthesizes vitamin $\mathrm{D}_{2}$ instead of vitamin $\mathrm{D}_{3}$. Typically, plants, yeasts and fungi synthesize vitamin $\mathrm{D}_{2}$ and animals synthesize vitamin $\mathrm{D}_{3}$, although exceptions to this general rule are known in the plant kingdom ${ }^{12,13,42,43}$. These plants synthesize vitamin $\mathrm{D}_{3}$ and metabolise it to $25(\mathrm{OH}) \mathrm{D}_{3}$ and $1,25(\mathrm{OH})_{2} \mathrm{D}_{3}{ }^{42,43}$. In certain plants vitamin $\mathrm{D}$ promotes differentiation and elongation of roots, possibly via the stimulation of calcium uptake $\mathrm{e}^{42,44,45}$. Whether vitamin $\mathrm{D}$ fulfils a function in invertebrates is not well understood ${ }^{13,46}$.

It has been suggested that vitamin $\mathrm{D}_{3}$ is an inactive end product ${ }^{13}$. However, its sterol precursor $7 \mathrm{DHC}$ is well studied as a precursor of insect moulting hormones (ecdysteroids) ${ }^{47-49}$. Unlike vertebrates, insects cannot synthesize sterols and therefore depend on either a dietary source or on symbionts, capable of de novo synthesis of sterols, to form these ecdysteroids, which are essential to attain normal growth, development and reproduction $^{4-50}$. In most insect species 7DHC is a minor sterol component, however, in yellow mealworms it comprises $17 \%$ of all sterols ${ }^{51}$. Figure 3 a shows that the vitamin $\mathrm{D}_{3}$ concentration in yellow mealworms reached a plateau in the third experiment. This could be because no more vitamin $\mathrm{D}_{3}$ was formed because the precursor 7DHC was limiting, or that vitamin $\mathrm{D}_{3}$ was still being formed and metabolised at the same rate. Alternatively, it might suggest that a quasi-equilibrium between 7DHC and its photoproducts had been reached, as occurs in vertebrate skin to prevent overproduction of previtamin $\mathrm{D}$, or that photodegradation of formed vitamin $\mathrm{D}$ was taking place ${ }^{6,52}$. Future studies should determine which vitamin D metabolites are formed and whether these metabolites have a function in insects.

\section{Conclusions}

This study indicates that: 1) migratory locusts, house crickets and yellow mealworms can synthesise vitamin $\mathrm{D}_{3}$ de novo after UVb exposure, but attain different concentrations, 2) higher vitamin D levels can be attained with exposure to higher UVb intensities, and 3) vitamin $\mathrm{D}_{3}$ levels in yellow mealworms increase until a maximum concentration is reached during prolonged UVb exposure.

\section{Methods}

Three experiments were conducted. In the first experiment, four insect species were exposed to a lamp which emitted a low UVb irradiance. In the second experiment, these four species were exposed to a lamp which emitted a higher UVb irradiance. In the third experiment, one insect species was exposed to the same UVb lamp as in the second experiment, but for different durations.

Animal housing and feeding. In the first two experiments migratory locusts (Locusta migratoria (L.); Orthoptera: Acrididae), house crickets (Acheta domesticus (L.); Orthoptera: Gryllidae), yellow mealworms (Tenebrio molitor (L.); Coleoptera: Tenebrionidae), and black soldier fly larvae (BSFL; Hermetia illucens (L.); Stratiomyidae: Diptera) were used. The first two species were provided by a commercial insect rearing company (Kreca, Ermelo, the Netherlands) and the latter two species were obtained from colonies maintained at the Laboratory of Entomology, Wageningen University, Wageningen, the Netherlands. In both these experiments the insects were subjected to one of two treatments; UVb exposed or UVb unexposed. In the third experiment only yellow mealworms were used.

All species were housed in enclosures proven suitable in prior investigations and provided with amounts of feed that allowed ad libitum feeding throughout the study ${ }^{53,54}$. Due to differences in housing and nutrient requirements, both the enclosures and provided diets differed between species.

Migratory locusts. Seventy five penultimate instar nymphs were housed in glass cages, designed for locust rearing, measuring either $60 \times 30 \times 35 \mathrm{~cm}(\mathrm{~L} \times \mathrm{W} \times \mathrm{H}$; three per treatment) or $50 \times 40 \times 35 \mathrm{~cm}$ (two per treatment). Five replicates were used per treatment. Heat was provided by a lamp (Model $100 \mathrm{~W}$, Philips, Eindhoven, the 
Netherlands), eight hours per day. Each enclosure was provided with $50 \mathrm{~g}$ fresh perennial ryegrass (Lolium perenne) from Unifarm (Wageningen University, Wageningen, the Netherlands) in the morning and with $75 \mathrm{~g}$ in the afternoon. Grass that had dried out was removed. In addition, each day the locusts were provided with $15 \mathrm{~g}$ of wheat bran (Arie Blok, Woerden, the Netherlands) and $30 \mathrm{~g}$ carrots (Daucus carota) from a local supermarket. The locusts developed large wings indicating adulthood after 21days in the first experiment and after 33 days in the second experiment. They were then manually taken from their cages.

House crickets. Fifty g of fourth instar nymphs were housed in a plastic enclosure (Clear Box XL, Bahag AG, Mannheim, Germany; $50 \times 35 \times 40 \mathrm{~cm}$ ) in which egg trays were placed to provide sufficient surfaces for resting. Five replicates were used per treatment. In the first experiment the crickets were provided with a chicken feed diet (Opfokmeel farmfood; Agruniek Rijnvallei Voer B.V., Wageningen, the Netherlands) whereas in the second experiment a commercial cricket feed (Kreca, Ermelo, the Netherlands) was used. Furthermore, in both experiments crickets were provided with $30 \mathrm{~g}$ carrots each day obtained from a local supermarket. Drinking water was provided via a water dispenser (Gebroeders de Boon, Gorinchem, the Netherlands) with a piece of paper tissue placed in the opening to prevent drowning. In both experiments most crickets reached the adult stage as indicated by the formation of large wings, after 31 days. They were then taken from their cages by hand.

Yellow mealworms. Twenty five g of larvae with a length of 3-5 $\mathrm{mm}$ were housed in a plastic crate measuring $50 \times 30 \times 10 \mathrm{~cm}$. Five replicates per treatment were used in the first experiment, and three replicates were used in the second experiment. All were provided ad libitum with commercial mealworm feed (Kreca, Ermelo, the Netherlands) and provided daily with $100 \mathrm{~g}$ carrots from a local supermarket. When the first pupa was seen in a container, 21 days after the start of the first and 29 days after the start of the second experiment, all mealworms were separated from their substrate with a $1 \mathrm{~mm}$ sieve.

Black soldier flies. One hundred g of three day old larvae were housed in lidless plastic enclosures (Faunarium type pt2665, Hagen, Holm, Germany) measuring $36 \times 23 \times 23 \mathrm{~cm}$. Five replicates were used per treatment. In the first experiment the larvae were provided with a chicken feed diet (Opfokmeel farmfood; Agruniek Rijnvallei Voer B.V., Wageningen, the Netherlands), whereas in the second experiment the larvae were provided with commercial cricket feed (Kreca, Ermelo, the Netherlands). Once per day $80 \mathrm{~g}$ of dry feed was mixed with $200 \mathrm{ml}$ of tap water and added to each container. In both experiments the first BSF reached the pre-pupal stage after seven days, as shown by the darkening of their integument. All BSF were then taken from their container rinsed with tap water to remove adhering feed residues, and subsequently dried on paper towels.

For all species each replicate batch of insects was then equally divided into subsamples by means of a two-way sample splitter (Model RT 25, Retsch, Haan, Germany) and stored in closed containers at $-20^{\circ} \mathrm{C}$ until further processing and subsequent analysis.

UVb exposure. Half of the specimens for each of the four species in experiment 1 and 2 were allocated to a treatment exposed to UVb, whereas the other half were allocated to a control treatment not exposed to UVb. Ultraviolet light was provided by means of $23 \mathrm{~W}$ fluorescent compact lamps (Model D3 ${ }^{+} 10 \% \mathrm{UVb}$, Arcadia, Surrey, UK). The lamps used in all three experiments had a similar spectral power distribution across visible wavelengths, but the UV irradiance was higher in the lamps used in the second and third experiment (Fig. 1a and b). All lamps were placed vertically in the middle of each enclosure and were switched on for 8 hours per day. The minimum distance between the UV lamps and the insects differed between species due to differences in cage dimensions; for the migratory locusts and BSFL this was $8.0 \mathrm{~cm}$, for the house crickets it was $10.0 \mathrm{~cm}$ and $11.0 \mathrm{~cm}$ for the yellow mealworms.

In the control treatments, a long drinking glass $(15 \times 7.5 \mathrm{~cm}$ Blokker BV, Amsterdam, the Netherlands $)$ was placed over the compact lamp which filtered out its UVb output (Fig. 1a). The outside of all enclosures were covered with dark plastic to prevent stray light, including UVb, from entering. During the experiments two UV meters were used, one to determine UVb irradiance (Solarmeter model 6.2, Solartech Inc., Harrison Township, MI, USA) and one to determine the UV index (Solarmeter model 6.5, Solartech Inc., Harrison Township, MI, USA).

For the migratory locusts, house crickets and yellow mealworms, the UV compact lamps were randomly rotated between the experimental treatment cages every three days, to correct for potential differences in UVb output between individual lamps. For the BSFL, which have a shorter life cycle, lamps were rotated daily. In both the first and second experiment the lamps were on for 8 hours per day.

In the third experiment the influence of UVb exposure time on vitamin $\mathrm{D}$ content was determined. For this, $30.0 \mathrm{~g}$ of yellow mealworm larvae, approximately $10 \mathrm{~mm}$ long, was placed in each of sixteen plastic containers $(16 \times 11 \times 6 \mathrm{~cm})$. Ten grams of mealworm feed and $10 \mathrm{~g}$ of carrots were added to each container at the beginning of the experiment and, for the treatments lasting longer than two days the same amount was added every two days. The yellow mealworms were then exposed for $0,5,10,20,30,45,60,90120,180,240,360,480,960,1920$ or $3840 \mathrm{~min}$ to the high irradiance compact lamps at a distance of $11.0 \mathrm{~cm}$. Animals in the latter three treatments were UVb exposed for 8 hours per day, and therefore harvested after 2, 4 or 8 days of exposure. One sample was analysed per time point.

Spectral and temperature measurements. UVb irradiance and UV index of all lamps were determined every five days. Measurements were taken perpendicular to the lamps at the minimum distance between the insects and the lamps (See Animal housing and feeding). Ambient room temperature was set at $24^{\circ} \mathrm{C}$ and monitored by means of a memory thermometer (TFA Dostmann GmbH, Reicholzheim, Germany). Enclosure 
temperatures during the day were measured by means of an infrared thermometer (Model DTG380, Reptile Technologies, Gorinchem, the Netherlands).

Emission spectra of both the low and the high irradiance lamps, with and without the control glass filter in place, were obtained using an Ocean Optics USB2000+ spectral radiometer with a UVb compatible fibre-optic probe with cosine adaptor (Ocean Optics Inc., Dunedin, Florida USA). Spectrometer recordings were made at a distance of $10 \mathrm{~cm}$ from the lamp surface.

Chemical analyses. At the start of the experiments samples were taken from all four species and their feed, and analysed in duplo for vitamin $\mathrm{D}_{2}$ and $\mathrm{D}_{3}$. Insect samples stemming from each replicate in the three experiments were analysed in simplo for vitamin $\mathrm{D}_{2}$ and $\mathrm{D}_{3}$. All insect samples were immersed in liquid nitrogen, homogenised with an analytical mill (Model 11a, IKA, Wilmington, USA) and analysed at TNO Triskelion (Zeist, the Netherlands).

Vitamin $\mathrm{D}_{2}$ and $\mathrm{D}_{3}$ concentrations in the feed were determined in accordance with Official Method of Analysis (AOAC) 2002.05. In short, after the addition of an internal standard (vitamin $\mathrm{D}_{2}$ ) and basic hydrolysis, vitamin $D_{3}$ was extracted with di-isopropyl ether. The fraction that contains vitamin $D_{2} / D_{3}$ was separated by preparative normal-phase liquid chromatography (LC). After evaporation and dilution in methanol-water, vitamin $\mathrm{D}_{3}$ was determined by reversed-phase LC with UV detection at $265 \mathrm{~nm}$. A separate test portion was analysed in parallel to confirm the absence of endogenous vitamin $\mathrm{D}_{2}$.

Vitamin $\mathrm{D}_{2}$ and $\mathrm{D}_{3}$ in the insect samples was determined in accordance with AOAC 2011.12. In short, an internal standard solution with deuterated vitamin $\mathrm{D}_{2}$ and vitamin $\mathrm{D}_{3}$ was added to a ground, homogenised sample. The sample was hydrolysed with ethanolic potassium hydroxide and vitamin $\mathrm{D}$ was extracted with di-isopropyl ether. The extract was evaporated, re-dissolved in methanol and vitamin $\mathrm{D}_{2}$ and $\mathrm{D}_{3}$ were analysed simultaneously using UPLC with tandem mass-spectrometry. The two methods above provide information on total vitamin $\mathrm{D}$ concentrations without distinguishing between their esterified and non-esterified forms. The presence of tachysterol in UVb exposed samples was investigated in accordance with Official Method of Analysis (AOAC) 2002.05. No tachysterol was detected, and peak purity of vitamin D was confirmed.

Statistical analyses. All data was analysed for significant differences $(\mathrm{P} \leq 0.05)$ with SPSS 24.0 (IBM Corporation, Armonk, NY, USA). Temperature and UV data were analysed with a paired sample t-test. Vitamin $\mathrm{D}$ data which were normally distributed and had equal variances were analysed via an independent sample t-test, else a Mann-Whitney U test was used. If vitamin D concentrations were below the limit of detection, this detection limit was used for statistical analysis.

Data availability. The datasets generated during and/or analysed during the current study are available from the corresponding author on reasonable request.

\section{References}

1. Reichrath, J., Lehmann, B., Carlberg, C., Varani, J. \& Zouboulis, C. Vitamins as hormones. Horm. and Metab. Res. 39, 71-84 (2007).

2. Holick, M. F. Vitamin D: a millenium perspective. J. Cell. Biochem. 88, 296-307 (2003).

3. Norman, A. W. From vitamin D to hormone D: fundamentals of the vitamin D endocrine system essential for good health. Am. J. Clin. Nutr. 88, 491S-499S (2008).

4. Huldschinsky, K. Curing rickets by artificial UV radiation. Deutsche Med Wochenschr 45, 712-713 (1919).

5. McCollum, E. V., Simmonds, N., Becker, J. E. \& Shipley, P. Studies on experimental rickets XXI. An experimental demonstration of the existence of a vitamin which promotes calcium deposition. J. Biol. Chem. 53, 293-312 (1922).

6. MacLaughlin, J. A., Anderson, R. R. \& Holick, M. F. Spectral character of sunlight modulates photosynthesis of previtamin $\mathrm{D}_{3}$ and its photoisomers in human skin. Science 216, 1001-1003 (1982).

7. Reerink, E. H. \& Van Wijk, A. The vitamin-D problem: The photochemical reactions of ergosterol. Biochem. J. 23, 1294-1307 (1929).

8. Holick, M. F. et al. Photosynthesis of previtamin $\mathrm{D}_{3}$ in human skin and the physiologic consequences. Science 210, 203-205 (1980).

9. Oonincx, D. G. A. B., Stevens, Y., van den Borne, J. J., van Leeuwen, J. P. \& Hendriks, W. H. Effects of vitamin $\mathrm{D}_{3}$ supplementation and UVb exposure on the growth and plasma concentration of vitamin $\mathrm{D}_{3}$ metabolites in juvenile bearded dragons (Pogona vitticeps). Comp. Biochem. Physiol. B: Biochem. and Mol. Biol. 156, 122-128, https://doi.org/10.1016/j.cbpb.2010.02.008 (2010).

10. Holick, M. F. Phylogenetic and evolutionary aspects of vitamin D from phytoplankton to humans. In Vertebrate Endocrinology: Fundamentals and Biomedical Implications Vol. 3. (eds Pang, P. K. T. \& Schreibman, M. P.) 7-43 (Academic Press, Inc. (Harcourt Brace Jovanovich) Orlando, 1989).

11. Rao, D. S. \& Raghuramulu, N. Vitamin $\mathrm{D}_{3}$ in Tilapia mossambica: Relevance of photochemical synthesis. J. Nutr. Sci. Vitaminol. 43, 425-433 (1997)

12. Chen, T. C., Lu, Z. \& Holick, M. F. In vitamin D Vol. 1 (ed Holick, M. F.) 35-60 (New York, 2011).

13. Bouillon, R. \& Suda, T. Vitamin D: calcium and bone homeostasis during evolution. BoneKEy Reports 3, 1-10, https://doi. org/10.1038/bonekey.2013.214 (2014).

14. Jones, G. Metabolism and catabolism of vitamin D, its metabolites and clinically relevant analogs. In Vitamin D second edition (ed. Holick, M. F.) 99-134 (Springer, 2010).

15. DeLuca, H. F. \& Schnoes, H. K. Vitamin D: recent advances. Annu. Rev. Biochem. 52, 411-439 (1983).

16. Gombart, A. F., Borregaard, N. \& Koeffler, H. P. Human cathelicidin antimicrobial peptide (CAMP) gene is a direct target of the vitamin D receptor and is strongly up-regulated in myeloid cells by 1,25-dihydroxyvitamin D3. The FASEB Journal 19, 1067-1077, https://doi.org/10.1096/fj.04-3284com (2005).

17. Liu, P. T. et al. Toll-like receptor triggering of a vitamin D-mediated human antimicrobial response. Science 311, 1770-1773 (2006).

18. Wang, T.-T. et al. Cutting edge: 1, 25-dihydroxyvitamin $\mathrm{D}_{3}$ is a direct inducer of antimicrobial peptide gene expression. J. Immunol. 173, 2909-2912 (2004).

19. Kamen, D. L. \& Tangpricha, V. Vitamin D and molecular actions on the immune system: modulation of innate and autoimmunity. J. Mol. Med. 88, 441-450 (2010).

20. Holick, M. F. Vitamin D deficiency. New Engl. J. Med. 357, 266-281 (2007).

21. Reichrath, J. Vitamin D and the skin: an ancient friend, revisited. Exp. Derm. 16, 618-625 (2007).

22. Finke, M. D. Complete nutrient content of three species of wild caught insects, pallid-winged grasshopper, rhinoceros beetles and white-lined sphinx moth. J. Insects as Food and Feed 1, 281-292, https://doi.org/10.3920/jiff2015.0033 (2015). 
23. Melo-Ruiz, V., Quirino-Barreda, T., Calvo-Carrillo, C., Sánchez-Herrera, K. \& Sandoval-Trujillo, H. Assessment of nutrients of escamoles ant eggs Limotepum apiculatum M. by spectroscopy methods. J. Chem. Chem. Eng. 7, 1181 (2013).

24. Finke, M. D. Complete nutrient composition of commercially raised invertebrates used as food for insectivores. Zoo Biol. 21, $269-285(2002)$

25. Finke, M. D. Complete nutrient content of four species of commercially available feeder insects fed enhanced diets during growth. Zoo Biol. 34, 554-564 (2015).

26. Finke, M. D. Complete nutrient content of four species of feeder insects. Zoo Biol. 32, 27-36 (2013).

27. Carman, E. N. et al. Photobiosynthetic opportunity and ability for UV-B generated vitamin D synthesis in free-living house geckos (Hemidactylus turcicus) and Texas spiny lizards (Sceloporus olivaceous). Copeia 2000, 245-250 (2000).

28. Holick, M. F. et al. Evaluation, treatment, and prevention of vitamin D deficiency: an endocrine society clinical practice guideline. J. Clin. Endocrinal. Metab. 96, 1911-1930, https://doi.org/10.1210/jc.2011-0385 (2011).

29. Olds, W. J. Elucidating the links between UV radiation and vitamin D synthesis: using an in vitro model, Queensland University of Technology (2010).

30. Cloudsley-Thompson, J. Studies in diurnal rhythms. IV. Photoperiodism and geotaxis in Tenebrio molitor L.(Coleoptera: Tenebrionidae). Physiol. Entomol. 28, 117-132 (1953).

31. WHO (World Health Organization). Global solar UV index: a practical guide (2002).

32. Holick, M. F. Sunlight, UV-radiation, vitamin D and skin cancer: how much sunlight do we need? In Sunlight, Vitamin D and Skin Cancer (ed. Reichrath, J.) 1-15 (Springer, 2008).

33. Boscoe, F. P. \& Schymura, M. J. Solar ultraviolet-B exposure and cancer incidence and mortality in the United States, 1993-2002. BMC Cancer 6, 264 (2006).

34. McKenzie, R., Smale, D. \& Kotkamp, M. Relationship between UVB and erythemally weighted radiation. Photochem. \& Photobiol. Sciences 3, 252-256 (2004).

35. USDA. (USDA, https://ndb.nal.usda.gov/ndb/, 2016).

36. Lock, E. J., Waagbø, R., Wendelaar Bonga, S. \& Flik, G. The significance of vitamin D for fish: a review. Aquacult. Nutr. 16, 100-116 (2010).

37. Barragan-Fonseca, K., Dicke, M. \& van Loon, J. Nutritional value of the black soldier fly (Hermetia illucens L.) and its suitability as animal feed-a review. Journal of Insects as Food and Feed, 1-16 (2017).

38. Bosch, G., van der Fels-Klerx, H., Rijk, T. C. D. \& Oonincx, D. G. Aflatoxin B1 tolerance and accumulation in black soldier fly Larvae (Hermetia illucens) and yellow mealworms (Tenebrio molitor). Toxins 9, 185 (2017).

39. Oonincx, D. G. A. B., Volk, N., Diehl, J. J. E., van Loon, J. J. A. \& Belušič, G. Photoreceptor spectral sensitivity of the compound eyes of black soldier fly (Hermetia illucens) informing the design of LED-based illumination to enhance indoor reproduction. J. Insect Physiol. 95, 133-139 (2016).

40. Liu, X. et al. Dynamic changes of nutrient composition throughout the entire life cycle of black soldier fly. Plos One 12, e0182601 (2017).

41. Houghton, L. A. \& Vieth, R. The case against ergocalciferol (vitamin D2) as a vitamin supplement. The American Journal of Clinical Nutrition 84, 694-697 (2006).

42. Boland, R. L. Plants as a source of vitamin $\mathrm{D}_{3}$ metabolites. Nutr. Rev. 44, 1-8 (1986).

43. Prema, T. \& Raghuramulu, N. Vitamin $\mathrm{D}_{3}$ and its metabolites in the tomato plant. Phytochem. 42, 617-620 (1996).

44. Jarvis, B. \& Booth, A. Influence of indole-butyric acid, boron, myo-inositol, vitamin D2 and seedling age on adventitious root development in cuttings of Phaseolus aureus. Physiol. Plant. 53, 213-218 (1981).

45. Buchala, A. \& Schmid, A. Vitamin D and its analogues as a new class of plant growth substances affecting rhizogenesis. Nature 280, 230-231 (1979).

46. Reichrath, J., Zouboulis, C. C., Vogt, T. \& Holick, M. F. Targeting the vitamin D endocrine system (VDES) for the management of inflammatory and malignant skin diseases: An historical view and outlook. Rev. Endocr. Metab. Disord., 1-13 (2016).

47. Svoboda, J., Kaplanis, J., Robbins, W. \& Thompson, M. Recent developments in insect steroid metabolism. Annu. Rev. Entomol. 20, 205-220 (1975)

48. Svoboda, J. A., Thompson, M. J., Robbins, W. E. \& Kaplanis, J. N. Insect steroid metabolism. Lipids 13, 742-753, https://doi. org/10.1007/bf02533755 (1978).

49. Behmer, S. T. \& Nes, W. D. Insect sterol nutrition and physiology: a global overview. Adv. Insect Physiol. 31, 1-72 (2003).

50. Robbins, W., Kaplanis, J., Svoboda, J. \& Thompson, M. Steroid metabolism in insects. Annu. Rev. Entomol. 16, 53-72 (1971).

51. Svoboda, J. \& Lusby, W. Variability of sterol utilization in stored-products insects. Experientia 50, 72-74 (1994).

52. Webb, A., DeCosta, B. \& Holick, M. Sunlight regulates the cutaneous production of vitamin D3 by causing its photodegradation. J. Clin. Endocrinol. Metab. 68, 882-887 (1989).

53. Oonincx, D. G. A. B. \& van der Poel, A. F. Effects of diet on the chemical composition of migratory locusts (Locusta migratoria). Zoo Biol. 30, 9-16, https://doi.org/10.1002/zoo.20308 (2011).

54. Oonincx, D. G. A. B., van Broekhoven, S., van Huis, A. \& van Loon, J. J. A. Feed conversion, survival and development, and composition of four insect species on diets composed of food by-products. Plos One 10, e0144601 (2015).

\section{Acknowledgements}

The authors acknowledge the Dutch ministry of Economic Affairs for their financial contribution through the STW project "In2Food". Arcadia is kindly acknowledged for the provision of the UV lamps used in the experiments. The authors thank Debbie van der Pol and Sabine van Woudenberg for their aid during the experiment. Lastly, the authors thank Mandy Decker for her photo contributions.

\section{Author Contributions}

D.O., P.v.K., M.F., F.B. and G.B. designed the experiments. P.v.K. and D.O. performed the experiments, F.B. performed the spectral analysis and M.V. performed the chemical analysis. D.O. and P.v.K. analysed the data and wrote the manuscript. All authors reviewed the manuscript.

\section{Additional Information}

Competing Interests: The authors declare no competing interests.

Publisher's note: Springer Nature remains neutral with regard to jurisdictional claims in published maps and institutional affiliations. 
(i) Open Access This article is licensed under a Creative Commons Attribution 4.0 International License, which permits use, sharing, adaptation, distribution and reproduction in any medium or format, as long as you give appropriate credit to the original author(s) and the source, provide a link to the Creative Commons license, and indicate if changes were made. The images or other third party material in this article are included in the article's Creative Commons license, unless indicated otherwise in a credit line to the material. If material is not included in the article's Creative Commons license and your intended use is not permitted by statutory regulation or exceeds the permitted use, you will need to obtain permission directly from the copyright holder. To view a copy of this license, visit http://creativecommons.org/licenses/by/4.0/.

(C) The Author(s) 2018 